\title{
Logics of structuring the elder care arrangements over time and their foundations
}

José de São José

\begin{abstract}
On the basis of family carers' perspectives, this article sets out to understand the logics of structuring care arrangements for older people over time, as well as to capture the roots of these logics. The data analyzed was gathered through qualitative research carried out in the Lisbon area. We found that elder care arrangements have been structured over time according to a logic designated by 'family primacy', in which family care has precedence over other modes of care provision. However, this logic is put into practice in different forms, associated with different social classes: 'restrictively' by family carers belonging to middle classes (they want to have a restricted involvement in care provision) and 'extensively' by family carers belonging to working classes (they are willing to have an extensive involvement in care provision). The results also reveal that the logic of 'family primacy' is rooted not only on 'familistic' values and norms but also on the negative impression family carers have of the quality of other modes of care provision. Lastly, it was also found that some elders agree with the logic of 'family primacy', whilst others idealize a slightly different logic ('conditional family primacy') which is compatible with the logic of 'family primacy', and still others who idealize a very different logic ('family exclusivity') which is not compatible with the logic of 'family primacy' and consequently could produce serious tensions between the elders and their family carers. It is believed that questioning the 'hierarchical compensatory model' proposed by Cantor is one of the contributions of this article.
\end{abstract}

Key words: care arrangements; logics of structuring; family carers; non-family carers; older people; Portugal; family primacy; quality of care; social policy 


\section{Introduction}

Contrary to what is found in lay discourses (e.g. media, church) and also in some scientific research (e.g. Popenoe 1993), in western societies intergenerational family solidarity is not in crisis, given that most of the recent research shows that the inter-relationships between family generations persist in different domains (e.g. Silverstein \& Bengtson 1997; Attias-Donfut et al. 2005), even in those countries with a high supply of formal services (Attias-Donfut \& Wolff 2000; Motel-Klingebiel et al. 2005). Nevertheless, if it is true that the intergenerational family solidarity is still alive, playing an important role in the well-being of the individuals, it is also true that it is restricted to close relatives (mainly in vertical line) and that it tends to be occasional or temporary rather than regular or permanent (Coenen-Huther et al. 1994; Bernard et al. 2000; Wall et al. 2001).

Care work is an important element of intergenerational family solidarity. Regarding elder care, it is known that the family continues playing a key role in meeting the elders' needs (Daatland \& Herlofson 2003; Hank 2007; Bernard et al. 2000), although there is a growing participation of carers outside the family in the care provision for this segment of the population (Glucksmann $\&$ Lyon, 2006; Huber et al. 2009). With regard to Europe, there is the idea that intergenerational family solidarity in relation to elder care is stronger in the South than in the North. This

difference is normally attributed to cultural factors: in the South familistic/collectivist social values prevail, whereas in the north, individualistic social values prevail. At the level of practical exchanges between generations, this North-South divide regarding elder care has conflicting evidence, since some studies point to a greater vitality of the intergenerational family solidarity in the South than in the North (e.g. Reher 1998; Hank, 2007; Haberkern \& Szydlik 2010), but others do not point to this simplistic division and reveal a more complex picture (e.g. Glaser et al. 2004; Dykstra \& Fokkema 2010). Conversely, at the level of preferences regarding elder care arrangements, this North-South divide seems to have more supporting empirical evidence. Several surveys carried out in Europe (e.g. Daatland \& Herlofson 2003; European Foundation for the Improvement of Living and Working Conditions 2004) reveal that in the Southern countries the preference is undoubtedly for family care arrangements, while in the vast majority 
of the Scandinavian countries the preference is for formal or institutional care arrangements, although family care arrangements also enjoy significant support.

The empirical research on the organisation of elder care arrangements and the logics associated with it has been guided by two main classical models: the 'hierarchical compensatory model' developed by Marjorie Cantor (1979) and the 'task specificity model' proposed initially by Eugene Litwak (1985). ${ }^{\text {i }}$

The 'hierarchical compensatory model', reformulated later by the same author, and acquiring the designation of 'model of the social care system' (Cantor 1991), stipulates that the selection of elders' carers is based on a hierarchy of preferences anchored in normative dispositions which attribute a high value to family care. The elders turn first to their relatives (husband or wife first; followed by daughters and sons; and then other relatives), then to friends and neighbours, and in last resort to the formal services. Irrespective of the type of care needed, the elders only turn to formal services when informal carers are unavailable or when they are unable to absorb the demands of providing care. The empirical evidence of the Cantor's model is partial and scarce, and it is restricted mainly to Anglo-American countries (see Qureshi \& Walker 1989; Penning 1990; Chappell 1991).

There is a significant body of research questioning the centrality of the normative principles in the distribution of family responsibilities related to elder care (e.g.: Finch \& Mason 1993; Arber \& Ginn 1995; Silverstein \& Bengtson 1997; Campbell \& Martin-Mathews 2000; Daatland \& Herlofson 2003). This research points out that these principles serve as mere guidelines stipulating the criteria that must be considered in the distribution of family responsibilities rather than what should be done in each specific situation, in one hand, and that the application of these guidelines is negotiated according to the circumstances in which the potential carers are included, on the other hand. Furthermore, it demonstrates that the allocation of family responsibilities and the organisation of care arrangements are shaped by other factors beyond the normative principles, such as the quality of the relationship between the elders and their relatives, the material and other resources owned by potential carers, and the similarity or nonsimilarity between the elders' sex and the potential carers' sex, amongst others. 
In turn, the 'task specificity model' suggests that the selection of carers by the elders and their relatives is not done based on a normative hierarchy of preferences, but rather on the degree of ability of the carers to provide specific tasks. The informal carers are viewed as particularly well suited to provide care that does not require technical knowledge and the formal carers are viewed as particularly well suited to provide demanding care from a technical point of view. The empirical evidence of this model is also scarce and restricted mainly to Anglo-American countries (see Fisher \& Eustis 1994; Penning \& Chappell 1990; Igel et al. 2009). There is more empirical basis supporting the thesis that informal and formal carers normally share the same tasks (no task specificity) and that the latter carers complement the informal carers' efforts (see Chappell \& Blandford 1991; Ward-Griffin \& Marshall 2003; Litwin \& Attias-Donfut 2009).

The research already undertaken on the organisation of elder care arrangements has undeniable contributions. However, we still do not have a thorough understanding of the care arrangements' trajectories over time, nor of the logics or dynamics which sustain them. This article aims to deepen this understanding.

\section{Purpose of the article and research approach}

In the context of the literature briefly reviewed above, this article intends to explore to what extent the structuring of the elder care arrangements have 'familistic' characteristics both in terms of practices and foundations/roots of the practices. In this sense, this article, based on the perspectives of a non-probability sample of Portuguese family carers, purports to answer the following research questions:

- Does the process of structuring the elder care arrangements follow, in practice, a 'familistic' logic similar to the logic of Cantor's model? Or does it follow (an)other logic(s)? 
- Are the identified logic(s) rooted exclusively in social values and norms internalised by the family carers and the elders, as proposed by Cantor's model? Or are they also rooted in other factors?

In the scope of this article, 'care' is conceptualised in the sense of 'social care', defined as '[...] the assistance and surveillance that is provided in order to help children or adults with the activities of their daily lives. Formal service provisions from public, commercial and voluntary organizations, as well as informal care from family members, relatives and others, such as neighbours and friends, are here included [...]' (Sipilä \& Kröger 2005: 2). On the other hand, 'care arrangements' are defined as solutions of care provision, which include one or more carers providing certain types of care tasks (who does what for the elders?). Lastly, the 'logics of structuring the care arrangements' refer to a linked set of practices related to the organisation of the care arrangements over time and the rationale associated with them. These logics were captured by analysing the trajectories of the care arrangements (initial configurations and subsequent configurations over time), as well as by the reasons interviewees gave for these trajectories. ${ }^{\text {ii }}$

Derived from the definition of social care presented above, in this article are used two main categories of carers: family carers (since the research in which this article is based focused on the perspectives of family carers), and other kinds of carers, including public sector carers, third/voluntary sector carers, formal and informal market carers, and informal (unpaid) carers (neighbours, friends, etc.). It was decided to use these categories rather than 'informal carers formal carers' for the following reasons. Firstly, although some studies have demonstrated that friends could be 'like family' in caring relationships (e.g.: Piercy 2001; Muraco \& FredriksenGoldsen 2011), in the data analysed in this article we do not find this kind of situation. Secondly, the formal carers who integrate the care arrangements here belong to different sectors of care provision (third sector and formal market). Thirdly, the categories 'informal carers - formal carers' do not include the informal market carers (e.g.: unregistered domestic workers). Thus, following Lyon and Glucksmann (2008), the provision of care by each kind of carers mentioned above represents different 'modes of provision'. 
This research was guided by the 'life course perspective', given that it is a theoretical and methodological perspective that focuses specifically on individual and family dynamics over time, as well as on individual and societal contexts that shape these dynamics. However, it also recognises that the individuals exert agency within certain social constraints (see Elder 1985; Settersten 2003). This perspective was particularly helpful to trace the trajectories of the care arrangements over time.

\section{Data and Methods}

The data analysed in this article was collected between 2005 and 2009 (in the Lisbon region) in the scope of the $\mathrm{PhD}$ thesis of the author. The research adopted a qualitative narrative approach focused on the 'caring stories' from the perspective of family carers: the trajectories carried out by family carers, the development of care arrangements over time, the tensions and problems associated with care arrangements, etc.

The data was gathered through semi-structured interviews which had a retrospective focus, as the bulk of the information collected is related to the interviewed carers' past. The interview guide was structured into four parts, each part covering several themes and sub-themes. The first part related to the socio-demographic characterization of the carer and to that of his/her family. The second part looked at the 'history of caring' and at the future plans concerning care arrangements (trajectories of the care arrangements over time; reasons for these trajectories; care tasks provided by family carers and other kinds of carers and time spent on the provision; future care arrangements, etc.). The third part was dedicated to the values and ideals regarding the caring for an older person (family duties; role of the State and role of other sectors, etc.). Finally, the fourth part focused on the interviewees' satisfaction in relation to care arrangements and on the impacts of caring (levels of satisfaction; the impact of caring on family carers' lives, etc.). 
The researcher interviewed 54 family carers, that were caring (or had cared during the past year) for an older dependent relative of ascending generation, and that lived in the metropolitan Lisbon area. 'An older dependent relative of ascending generation' was defined as a relative of the interviewee, through blood-relation or affinity (ascendant relative of the spouse of the interviewee), belonging to the ascending family generation, 65 years or older, and in need of regular care from others in order to carry out his/her basic daily living activities. The large majority of the family carers interviewed are daughters of the elders, although some sons, daughters-in-law, grandchildren, nieces and also the wife of an elder's grandchild were also interviewed (for a brief characterization of the sample, see Table 1).

The process of interviewees' selection was oriented by the principle of 'sampling for heterogeneity'. It was our concern that carers with different characteristics were selected. These differences were in terms of variables such as gender, age, kin relationship with the older person, employment status, marital status, parenthood status, and level of income and education. Also of concern was that the sample took into consideration diversity in terms of the level of disability of the older person. As such, a combination of sampling techniques in the selection of interviewees - convenience sampling, 'snowball' sampling, and 'purposive' sampling - was used. Twelve interviewees were selected with the collaboration of a non-profit Portuguese institution: Santa Casa da Misericórdia de Lisboa. ${ }^{\text {iii }}$ Only a minority of selected carers did not show a willingness to collaborate in the research. In these cases, the selected family carers indicated other family members who were available to collaborate.

Most of the interviews were conducted at the University of Lisbon, while others were held at the interviewees' homes. The interviews lasted, on average, two hours and we believe that the venue where they were conducted did not influence the procedure. All the interviews were audio taped and fully transcribed. The transcriptions were analysed according to the 'Framework Analysis' principles. Briefly, the central component of this approach is the 'thematic framework', which is used to organize and classify data according to themes and sub-themes, concepts and emergent categories. Three main steps are involved in 'Framework Analysis': preparation and organisation of data (familiarizing with the data, identifying emergent themes and sub-themes, etc.), 
descriptive analysis (identifying dimensions, creating typologies, etc.), and explanatory analysis (detecting patterns and associations, developing explanations of identified patterns and associations, etc.). The choice of this analytical approach is justified by the suitability of the 'thematic framework' for analysing data collected through semi-structured interviews. This analytical approach is fully discussed in Ritchie \& Lewis (2003), amongst others.

\section{Results}

This section analyses the organisation of the elder care arrangements over time, the trajectories of care arrangements, as well as the reasons identified by the interviewed family carers for these trajectories.

\section{Trajectories of the elder care arrangements}

Some care arrangements had always been exclusively composed of family carers (family care arrangements), whilst others started by including only family carers but, at a certain point in time, began to include carers outside of the family (transition from family care arrangements to mixed care arrangements). There are also care arrangements that always included family carers and other kinds of carers (mixed care arrangements).

\section{Always Family Care}

Most of the family care arrangements are shared (with the exception of few cases, between the interviewed carer and other family carer). These shared family care arrangements are represented by six daughters, two daughters-in-law and one granddaughter, who have been providing care 
from 2 to 4 years, except two who have a longer caring trajectory. Most of these carers live with their elders and share the care provision with co-resident relatives.

The family carers who have shared the care work with other relatives opted for this arrangement because, according to their views, the option of a situation of 'solo caring' would not be appropriate to satisfy all the care needs of the elders (these always had medium levels of disability). And/or it would imply very high costs for the 'solo carers' (negative interferences in domains of their lives such as leisure, personal time and even professional activity). Some of these carers ( 3 cases) also have young children (under 12 years old), which contribute to the need to share the elder care. In any case, these family carers had the option of resorting to other kinds of carers rather than family cares, but this did not happen for the following four inter-related reasons. Firstly, all these family carers argue (although some more explicitly than others) that the family should be the first (and main) provider of care for older people. Resorting to other modes of care provision should only be considered if the family is unable to absorb all the care demands.

'Q: Who should have the main responsibility of providing care for older people? The family, the State, or both? A: The family. Q: Why? A: Because of emotional ties. First it should be the family, especially those who are closer (emotionally) to the elders. The services should only be called in when the family can not provide the care. When the family can not, then others (beyond the family) should help' (Interview n'1). ${ }^{\text {iv }}$

Secondly, all these family carers have a negative impression on the quality of other modes of care provision, especially the public and third/voluntary modes. This impression derives from media news (most cases), acquaintances' experiences or personal experiences. Most of these family carers explicitly emphasise that the care they provide is of better quality than the care provided by other kinds of carers. 
'The people who work in the services (for older people) do not have the required qualification, they do not have skills and they do not have the patience for dealing with the elders' (Interview $\left.\mathrm{n}^{\circ} 16\right)$.

II would not like that other people (non-relatives) provide care to my mum, mainly the body hygiene. Q: Why? A: Because I give my full attention to my mum, I take very good care of her, and I think that people outside the family would not take as good care of her as I do, it would be a cold thing and it would also be rushed' (Interview $\left.\mathrm{n}^{\circ} 14\right)$.

Thirdly, in some cases the elders do not want to receive care from strangers. Some of their family carers have already felt the need to turn to other modes of care provision, which conflicts with the desire of the elders. While some of these family carers respect the will of the elders and accept being over-worked with the provision of care, others have difficulties in accepting it, which causes some tensions between them. Lastly, it is important to mention that there were other relatives with availability to provide care.

There are five family carers (four daughters and one son) who have been 'solo carers', since they have not yet felt the need to request support from other carers (family carers or other kinds of carers). Four of these carers were already retired when the elders began to need care and they have acted as 'solo carers' because, according to their views, they have had available time to provide care, and the provision of care has not produced significant negative interferences in the more valued domains of their lives (the elders have low/medium levels of disability). The fifth carer, a daughter, has cared while working outside the home (full time job), but as her mother has a low level of disability, she has not yet considered the possibility of asking for support, given that she has managed to combine care with her full time job. It is worth mentioning that these family carers, providing care from 2 to 5 years, do not have other caring responsibilities, which facilitates the maintenance of the 'solo carer' situation.

Lastly, there is one case in which the care arrangement started as non-shared family care and later changed to shared family care. This transition took place because the elder became more 
dependent, and the carer interviewed, a daughter working full-time, felt the need to request support. It was her sister who began to help her, because she had available time (she had a parttime job). Additionally, the father does not like strangers in the house. These two carers, not living with their parents and sharing the care provision for about one year and half, have not yet felt the need to turn to other kinds of carers (they do not have other caring responsibilities).

In relation to the plans concerning future care arrangements, the family carers who integrate family care arrangements (shared or not shared) are considering turning to other modes of care provision rather than to family care when the provision of care becomes too demanding from the point of view of time and energy. They do not consider the maintenance of their current family care arrangements as a viable solution, given that there are no other potential family carers, or there are some but they are unavailable to provide care on a regular basis (in some cases this unavailability is interpreted by the interviewed carers as lack of willingness, which produces some tensions and conflicts). However, some will try to postpone resorting to other kinds of carers for as long as possible, because the elders do not want to receive care from strangers. This is the case for the following daughter:

'We will keep him at home without resorting to services until we can. My father does not like strangers at home’ (Interview $\left.\mathrm{n}^{\circ} 16\right)$.

It is relevant to add that all of these family carers (as well as the remaining family carers interviewed) have clear preferences regarding social services: they will turn preferably to domiciliary care or day centres, in order to maintain the elders at home for as long as possible. A nursing home or other type of residential care is always considered to be the last option because, from the perspective of these carers, 'putting the elder person in a nursing home is equivalent to giving them an earlier death' (Interview n44).

Lastly, it is worth mentioning that the level of involvement in care provision that these family carers are willing to have varies between them. The majority want to continue to have a 
restricted involvement (they will provide care whilst the care work does not produce significant negative interferences in any of the domains of their lives, such as professional life, leisure and personal time), while others (a minority) are willing to have an extensive involvement (they are willing to provide care whilst they have good health, and accept the sacrifices required in certain domains of their lives such as leisure, personal time and even professional life). Consequently, it is plausible that the former will turn to other modes of care provision sooner than the latter. Interestingly, except for very few cases, the family carers who want to have a restricted involvement have higher levels of educational and financial resources than the family carers who are willing to have an extensive involvement.

\section{Transition from family care to mixed care}

Thirteen care arrangements initially included only family carers, but at a certain point in time began to include also other kinds of carers. These mixed care arrangements took on different configurations because they included different kinds of carers, but none of these worked within institutional settings.

The transitions from family care to mixed care occurred because, from the perspective of the carers interviewed, it was not possible to maintain a family care arrangement. This impossibility was related to two main situations. Firstly, the care work became more demanding in terms of time and energy, as a result of the deterioration of the elders' state of health, and the family was unable to handle the new demands. Here is the testimony of a daughter who tried, in conjunction with her sister, to continue providing care to her mother who started to need intimate care (body hygiene):

'We (interviewed carer and her sister) could not leave our houses, to wash and clean her and get to work at eight. I could never get there, to my mother's house, before seven. So, I could not care for her and be at work at eight. We tried, but we could not, it was very tight' (Interview $\mathrm{n}^{\circ} 48$ ). 
Secondly, in one case the elder began to need intimate care but she refused to receive it from her son (who was willing to provide it) due to modesty, and there were no other relatives available to provide it. This son turned to the formal market (domiciliary care from a private company). The issue of modesty and its role in prompting people to resort to carers outside the family is illustrated in the account of this son:

'Do you provide the body hygiene? No. She does not let me do it because of modesty. For example, now the girl of domiciliary care is doing her body hygiene but the bedroom's door is closed. As she has no one besides me, I had to find an alternative' (Interview $\mathrm{n}^{\circ} 9$ ).

Let us look in more detail to the cases inserted in the first situation. Here we find family carers who have full-time jobs and others who have not been working outside the home since the elders began to need care (retired or unemployed). The carers who have a professional employment (five daughters, two sons, and the wife of the elder's grandson) also agree on the principle that the family should be the main care provider for older people. Furthermore, they also think that other modes of care provision offer poor quality. However, they were unable to maintain a family care arrangement. Some had to turn to other mode of care provision because they could not combine the new care demands with professional responsibilities, while others mentioned that they could not combine the new care demands not only with the professional responsibilities, but also with other domains of their lives such as leisure, family life and personal time. The former sacrificed some domains of their lives from the beginning of their caring trajectories, such as leisure and personal time, which allowed them to maintain the care arrangements based exclusively on the family for a while (more than one year). They only resorted to other modes of care provision when they became aware that maintaining a family care arrangement would also imply sacrificing, at least in part, their jobs or, alternatively, the well-being of the elders. On the other hand, the latter family carers resorted to other modes of care provision as soon as they began to feel negative interference of the new care demands on leisure and personal time (however, some of these carers have been providing care for more than 5 years). This implied that the former turned to other modes of care provision later than the 
latter. It is interesting to verify that, with the exception of very few cases, the carers who turned sooner to other modes of care provision have higher educational and financial resources than the carers who turned later to other modes of care provision.

In relation to the family carers who have not been working outside the home (three daughters and one daughter-in-law), the reason for resorting to other modes of care provision was the intensification of physical and psychological exhaustion that they were already feeling. They were full time carers for many years (more than 6 years), providing all the care needed by the elders (in most of the cases the care needed was very demanding) without a regular help from other relatives (they had no other relatives available to provide care). In their opinion, the other modes of care provision should only be requested when the family can not satisfy all the needs of the elder. Moreover, and perhaps this is the most important factor that explains their 'heavy' caring trajectories, these family carers were willing to have an extensive involvement in care provision. Added to this, they also have a negative impression of the other modes of care provision. However, when the elders began to need more demanding care in terms of time and energy, they were 'forced' to turn to other mode of care provision (many of these elders become bedridden). Thus, contrarily to what happens with the 'solo carers' mentioned in the trajectory 'always family care', these family carers, also 'solo carers', had to turn to domiciliary care from a not-for-profit institution, because they were providing 'heavy' care for many years. These female carers have four years of compulsory schooling, except for one that completed high school. All of them have low financial resources.

\section{Always Mixed Care}

In twenty six cases the care arrangements have always been mixed or were exclusively family for a very short period of time (up to 3/4 days). In the large majority of these cases, other kinds

of carers started caring immediately after the older person began to need social care (for 
example, after the older person left hospital), whilst in the other cases, other kinds of carers started providing care a few days after the older person started to need social care. ${ }^{\mathrm{v}}$

These care arrangements have always been mixed because, with the exception of some cases (addressed later), it was not possible to implement a care arrangement based exclusively on the family. This impossibility was related to two types of situations (cases fit mainly within the first situation). In the first situation, the care work was very demanding from the very beginning, and the family was not able to handle all the demands:

'Even if I was willing to care for my mum by myself, without any kind of help from services, I couldn't, it would be impossible, because I and my husband have to work. Therefore, before my mum had left the hospital I already had arranged domiciliary care' (Interview n⿳0 38 ).

In the second situation, the elders refused to receive intimate care from their family carers of the opposite sex, and there were no other relatives available to provide it.

These two situations are very similar to those that are associated with the transitions from family care to mixed care. However, with respect to the first situation there are some aspects that should be emphasised.

The family carers who fall within the first situation (six daughters, four sons, two daughters-inlaw, two granddaughters and two nieces) also agree with the principle that the family should be the main provider of elder care, and that resorting to other modes of care provision should only occur when the family can not deal with all the caring demands. Furthermore, they also have a negative impression of the other modes of care provision. Nevertheless, it was not possible to put a family care arrangement into practice, given that the implementation of a family care arrangement would imply that the family carers had to sacrifice important domains of their lives such as employment, or that the elders (with medium/high levels of disability) stayed home alone 
for very long hours (however, in some cases, the mixed care does not prevent the elders staying home alone for one/two hours per day). Even those family carers that were willing to have an extensive involvement in care provision were aware that a family care arrangement would only be viable if they accepted one of these two negative consequences. It is important to stress that almost half of these family carers had young children when the elders started needing care, which contributed to the impossibility to organise a elder care arrangement based solely on family. In some cases, the distance between the elders' homes and the family carers' homes also contributed to the impossibility of the implementation of a family care arrangement. With the exception of two cases, these family carers have been providing care for less than 4 years.

In relation to the level of involvement in care provision, the cases within this first situation confirm the association that was already mentioned: the majority of the family carers who are willing to have an extensive involvement in care provision have lower educational and financial resources than those who opt for a restricted involvement.

In the exceptional cases mentioned earlier, which are represented by eight daughters, it would have been possible, at first sight, to implement a care arrangement based exclusively on family, given that the elders do not need demanding care in terms of time and energy. However, in practice, the care arrangements have always been mixed because the family carers interviewed already benefited from the services of a domestic worker when the elders started to need some care. These family carers have high educational and financial resources.

\section{Logics of structuring the care arrangements, their foundations and the elder's preferences}

Our data reveal that some family carers preferred to turn to other relatives, instead of other kinds of carers, when they realised that it would not be viable to create or to maintain a situation of 'solo caring' (non-shared family care). We also found that the family carers who integrate family 
care arrangements expect to turn to other kinds of carers when the care work becomes too demanding, not because they prefer mixed care arrangements, but because they consider that maintaining the respective family care arrangements will not be viable.

It was also revealed that other family carers started implementing care arrangements based exclusively on the family, but at some point in time they felt the need to integrate other kinds of carers. This transition occurred because, according to the family carers interviewed, it was not possible to maintain a family care arrangement.

Lastly, we verified that in some cases the care arrangements have always been mixed because the family carers could not implement a care arrangement based exclusively on the family.

The impossibility of creating or maintaining a family care arrangement was associated with the scarcity of other family carers and with the inability of the current family carers to handle all the care demands without heavy costs for them and/or for the elders. This inability was related not only with the elders' level of disability but also, in some cases, with the existence of other caring responsibilities (having young children) and, in other cases, with the long duration of the caring trajectory. Curiously, there are cases in which the impossibility of creating or maintaining a family care arrangement was not based on the inability of the family but rather on the refusal of the elders to receive intimate care from family carers of the opposite sex.

Therefore, based on the views of the family carers interviewed, we can state that the processes of structuring the care arrangements over time have been based, in practice, on a logic that can be designated by 'family primacy'. This logic can be characterised as follows: the family carers prefer to implement, in the first place, family care arrangements, and they only consider turning to other modes of care provision when they perceive that a family care arrangement is not possible to create or to maintain. According to this logic, the other modes of care provision have a subsidiary role, as they are only considered when the family care solutions are perceived as non-viable. In this sense, for the interviewed family carers, resorting to other modes of care 
provision is like a 'necessary evil', given that these are negatively viewed by them in terms of quality.

Interestingly, the logic of 'family primacy' has been carried out in all cases analysed, but an important nuance was found: the component of the logic 'when it is not possible to implement or to maintain a family care arrangement' is not conceived in the same form by all the family carers interviewed. For some, this component means 'when the caring responsibilities produce negative interferences virtually in any domain of my life such as professional activity, leisure, personal time, etc.', for others it means 'when the caring responsibilities produce negative interferences on my job, given that I am willing to accept negative interferences on leisure and personal time', and there are also a few family carers for whom it means 'when the caring responsibilities produce negative interferences on my health, given that I am willing to accept negative interferences on the remaining domains of my life'.

These different forms of understanding the same principle reflect different conceptions of the role of family carer. Some family carers interviewed want to 'keep intact' virtually all domains of their lives, imposing restrictions on their participation in care provision, and consequently they turned (or are thinking about turning) to other modes of care provision in early stages of their caring trajectories or as soon as they began (or begin) to feel negative interferences in any domain of their lives. On the other hand, others are willing to sacrifice several domains of their lives such as leisure, personal time (and in few cases even professional lives) in order to have an extensive involvement in care provision, and consequently they turned (or are thinking about turning) to other modes of care provision in later stages of their caring trajectories. Thus, we can say that the former have structured the care arrangements according to a logic of 'restricted family primacy' and the latter according to a logic of 'extensive family primacy'. This shows that, contrarily to what one might think, resorting to other modes of care provision in early stages of the process of structuring the care arrangements, or as soon as the family carers begin to feel negative impacts of caring in any domain of their lives, is compatible with the logic of 'family primacy'. 
It seems that cultural and material factors explain the nuance that we have just described, given that, with the exception of a few cases, the logic of 'restricted family primacy' is represented by family carers with high educational and financial resources, and the logic of 'extensive family primacy' is represented by family carers with lower educational and financial resources.

The data also allowed us to capture, although from the perspectives of the family carers interviewed, the preferences of the elders regarding the appropriate care providers. Interestingly, while some apparently agree with the logic of 'family primacy' irrespective of the type of care needed, others impose a condition: if they need intimate care the respective family carer has to be of the same sex; alternatively, if there is no family carer of the same sex, they prefer to receive this type of care from other kinds of carers. In the cases where this last situation occurs, the preferences of the elders functioned as an 'accelerator' for the resort to other modes of care provision. Thus, we can say that these elders agree with a logic of structuring the care arrangements that can be designated by 'conditional family primacy'. From the perspectives of the family carers interviewed, this logic forms the basis of one of the factors that made it impossible to create or to maintain a care arrangement based exclusively on the family. Therefore, this logic is not incompatible with the logic of 'family primacy', despite producing some tensions between the elders and their family carers.

We also saw that in other cases the elders do not idealize a logic similar to that of 'family primacy', as they do not want to receive any type of care from strangers. In contrast to the cases referred above, in these the preferences of the elders have served as a 'decelerator' for the resort to other modes of care provision. In these cases the elders agree with a logic of structuring the care arrangements that goes beyond the 'family primacy' and that we can designate by 'family exclusivity'. This logic has not functioned as a barrier to the logic of 'family primacy', given that the elders who defend it belong to the cases where there has been no need to resort to other modes of care provision. However, in the future it can produce serious tensions and conflicts between the elders and their family carers, eventually compelling the process of structuring the care arrangements to follow, in practice, a logic different from that of 'family primacy'. 
Turning to the foundations of the logic of 'family primacy', two different factors were identified that can explain why the care arrangements analysed have been structured, in practice, according to this logic. The social values and norms regarding the elder care is one of the factors, given that the family carers interviewed argue (although some more explicitly than others) that the family should be the first provider of care and that resorting to other modes of care provision should only be considered when the family can not handle the care demands. As we have seen, despite the fact that every family carer interviewed places a high value on family care, some want to have a 'restricted' involvement in care provision and others an 'extensive' involvement.

The second factor in which the logic of 'family primacy' is rooted is the negative impression that the family carers interviewed have regarding other modes of care provision, especially of the public and third/voluntary modes of provision. This impression, that is disseminated in Portuguese society (Sousa 2004; São José \& Wall 2006), creates a reluctance to use other modes of care provision, as the family carers only resort to them when they consider that it is not viable to create or maintain a care arrangement based exclusively on the family. Although there are still some shortcomings in terms of the availability of social care services in Portugal, this aspect was not identified as a major problem by the interviewees, but rather the quality of these services. It is plausible that this negative image reinforces the value placed on family care.

\section{Discussion and main conclusions}

In relation to the first research question, the results show that the process of structuring the care arrangements over time has 'familistic' elements, as in all cases analysed this process was in line with the logic of 'family primacy'. This logic has some similarities with the logic of Cantor's model, but differs from it insofar as its practical implementation has an important nuance. Apart from a few exceptions, the logic of 'family primacy' is carried out in a 'restrictive' form by the families belonging to middle classes and in an 'extensive' form by the families belonging to working classes. Thus, these results show that the practical implementation of the logic of 
'family primacy' is mediated by social class, since the conception of the role of family carer tends to vary according to social class. This questions the idea that family carers, in general, are willing to have a high involvement in the provision of care, which is relevant from the point of view of social policy and professional practice.

The different forms through which the logic of 'family primacy' is implemented is certainly related to factors of cultural and material nature. There is empirical evidence showing that more advantaged social classes tend to express weaker levels of family duties (Coenen-Huther et al. 1994; Connidis 2001). On the other hand, there is also some research revealing that these classes cope better with the bureaucracies and with the interaction with social services than the working classes (e.g.: Twigg \& Atkin 2002). Despite this, I put the hypothesis that the possession of financial resources has a predominant role, in the sense that high levels of these resources lead to a loosening of normative principles.

We also found that in both forms of implementation of the logic of 'family primacy' the family carers do not conceive the other kinds of carers as 'real partners' in the provision of care, but rather as 'last resort carers' to whom they only turn when they begin to feel that the provision of care solely based on family begins to produce negative interferences in their lives and/or the elders' lives. This is particularly relevant for social policy and professional practice, since in a situation like this the relationship between the family carers and other kinds of carers is marked by some distrust by the family carers regarding the quality of other modes of care provision, making it difficult to build a strong partnership between the two groups of carers. Consequently, the possibility of building a stronger partnership between the family carers and other kinds of carers will only be achieved through improving the quality of services provided by other kinds of carers.

Regarding the second research question, we also found 'familistic' elements in the roots/foundations of the logic of 'family primacy', as the family carers think that the family should be the first and the main provider of elder care. ${ }^{\mathrm{vi}}$ It is important to add that in Portugal the filial duty of providing care for parents is still fairly institutionalized, as there is a strong support 
for the principle that the children should provide care for their older parents in their own homes or in the parents' homes (Vasconcelos 1998). However, based on the results presented above, it is not tenable to say that the logic of 'family primacy' is based solely on 'familistic' values and norms, since the negative impression of other modes of care provision also plays a very important role. In this regard, it is interesting to note that Portugal is one of the EU countries where we find the most negative evaluations of the quality of domiciliary care for older people (Eurobarometer 2007). ${ }^{\text {vii }}$ As we had the opportunity to see, the interviewed family carers underline three main negative aspects related to other modes of care provision, especially the public and third/voluntary modes of provision: cold, rushed and inattentive. These interviewees believe that family care have, precisely, the opposite characteristics. They attribute to emotional ties a vital role in caring relationships, something that they do not identify in other modes of care provision. Thus, it seems that these interviewees make a contrast between the 'labour of love' of family care and the 'bureaucratic rationality' of social services. This contrast contributes to create favourable conditions for the practical implementation of the logic of 'family primacy'. However, although the feminist literature on elder care had created the idea that family care was equal to 'good care', as mentioned by Ungerson (1990), the family care is not always 'good care', as revealed by some studies on abuse and violence related to care (e.g.: Forbat 2005; Friedman et al. 2011), and the other modes of care provision are not necessarily 'bad care', as suggested by King (2007) and Lloyd (2003).

In this sense, we can hypothesise that a better image of other modes of care provision in the future may imply an eventual shift in the logic of structuring the care arrangements towards a weakening of the 'family primacy'. Improving the quality of social care services is one of the current priorities of social policies in Portugal.

The importance of the interviewees' perceptions about the quality of the social services constitutes another point of questioning the logic of Cantor's model, since this model is essentially based on one factor: the social values and norms. On the other hand, this finding goes in line with the most recent research, which underline the multiplicity of factors that intervene in 
the organisation of elder care arrangements (e.g.: Finch \& Mason 1993; Arber \& Ginn 1995; Silverstein \& Bengtson 1997; Campbell \& Martin-Mathews 2000; Daatland \& Herlofson 2003).

Therefore, this article highlights that the structuring of elders' care arrangements follow, in practice, a 'familistic' logic that we designated by 'family primacy', but the roots/foundations of this logic are not as 'familistic' as one might think, since it is based not only on 'familistic' values but also on the negative impression that the family carers have of the quality of other modes of care provision.

Another interesting finding emerged from the data: there are elders who idealize a slightly different logic from the logic of 'family primacy', namely a logic of 'conditional family primacy', and others who idealize a very different logic, namely a logic of 'family exclusivity'. Whilst the logic of 'conditional family primacy' is not incompatible with the logic of 'family primacy', the same cannot be said in relation to the logic of 'family exclusivity'. This shows that the elders have an active role in the organisation of care arrangements and that their ideas regarding this organisation do not necessarily coincide with the ideas of the family carers. This latter point shows us, as other studies had already shown (e.g.: Arber \& Ginn 1995; Campbell \& MartinMathews 2000), that in some cases there are restrictions, imposed by the elders, to the provision of intimate care by family members. This is relevant from the point of view of public policies, both in terms of social services' organisation and elders' rights. On the other hand, the latter point also draws our attention to the possibility of the elders wishing to receive certain types of care from other kinds of carers rather than from family carers. This possibility, found in the 'conditional family primacy', is not foreseen in Cantor's model.

The divergence between the family carers and the elders regarding the organisation of care arrangements is, as we saw, a potential source of tensions and conflicts. This indicates that the decision making process regarding care arrangements is not entirely unproblematic (there are other sources of tensions and conflicts which were not explored in this article). 
Finally, just some brief ideas for future research. It would be interesting to further explore the reasons why some family carers want to have a restricted involvement in care provision and others an extensive involvement. The level of involvement has to do with normative principles, emotional ties or with the circumstances (non-employment, no other family responsibilities, etc.). Moreover, more attention should be given to the role of the elders in the process of structuring their care arrangements, taking into account the negotiations that take place between them and their family carers.

\section{Endnotes}

\footnotetext{
${ }^{\mathrm{i}}$ See also Litwak, Jessop and Moulton (1994).

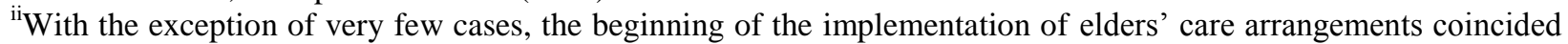
precisely with the beginning of caring trajectories of the family carers interviewed. In exceptional cases, the care arrangements already existed when the family carers interviewed began providing care, but the inclusion of these did not change the care arrangements configurations (ex.: the care arrangement was mixed, that is, composed by family carers and other kinds of carers, and it remained that way after the inclusion of the carer interviewed).

iii This institution belongs to the third/voluntary sector and provides several types of social care services for children and adult dependent people.

iv The quotations were translated from Portuguese to English by the author. It is believed that the core meaning of the interviewees' discourse was not modified trough the translation.

${ }^{\mathrm{v}}$ Some care arrangements which were always mixed suffered some changes over time, but these changes did not lead to an alteration in their basic configurations, that is, the care arrangements continued to be mixed.

${ }^{\mathrm{vi}}$ As the sample is constituted only by relatives who are carers, it is not surprising that all of them agree with the statement that the family should be the main carer. Probably, they are carers because they agree with this. If we had interviewed relatives of elders who have care arrangements solely based in cares outside the family, the views probably would not be exactly the same. However, these latter situations are residual in Portugal.

vii The quality of Portuguese social services has improved over time, however the community services (domiciliary care and day centres) continue under a certain 'halo effect' which derives from the bad reputation of residential care. Nevertheless, it is interesting to verify that it was only in 2008 that the Government established regulations to ensure minimal standards of quality.
} 


\section{Acknowledgements}

This paper has been partially supported by the Portuguese Foundation for Science and Technology (FCT). 


\section{References}

ARBER, S. and GINN, J. (1995) 'Gender differences in informal caring', Health and Social Care in the Community, vol. 3, issue 1 pp.19-31.

ATTIAS-DONFUT, C and WOLFF, François-Charles (2000) 'Complementarity between private and public transfers'. In Arber S and Attias-Donfut C (Eds.) The Myth of Generational Conflict: the family and state in ageing societies, London and New York: Routledge.

ATTIAS-DONFUT, C., OGG, J. and WOLFF, F. (2005) 'European patterns of intergenerational financial and time transfers', European Journal of Ageing, vol. 2, no. 3 pp. 161-173.

BERNARD, M., PHILlIPS, J., PHILlIPSON, C. and OGG, J. (2000) 'Continuity and Change: the family and community life of older people in the 1900s'. In Arber S and Attias-Donfut C (Eds.) The Myth of Generational Conflict: the family and state in ageing societies, London and New York: Routledge.

CAMPBELL, L. D. and MARTIN-MATTHEWS, A. (2000) 'Primary and Proximate. The Importance of Coresidence and Being Primary Provider of Care for Men's Filial Care Involvement', Journal of Family Issues, vol.21, no. 8 pp.1006-1030.

CANTOR, M. H. (1979) 'Neighbors and friends: an overlooked resource in the informal support system', Research on Aging, vol. 1, no. 4 pp. 434-463. 
CANTOR, M. H. (1991) 'Family and Community: Changing Roles in an Aging Society', The Gerontologist, vol. 31, no. 3 pp. 337-346.

CHAPPELL, N. (1991) 'In-group differences among elders living with friends and family other than spouse', Journal of Ageing Studies, vol. 5, issue 1 pp. 61-76. [doi:10.1016/08904065(91)90025-N]

CHAPPELL, N. and BLANDFORD, A. (1991) 'Informal and formal care: exploring the complementarity', Ageing \& Society, vol. 11, issue 3 pp. 299-317.

COENEN-HUTHER, J., KELlERHARLS, J. and ALlMEN, M. V. (1994) Les Reséaux de Solidarité dans la Famille, Lausanne: Réalités Sociales.

CONNIDIS, I. A. (2001) Family Ties and Aging, London: Sage publications.

DAATLAND, S. and HERLOFSON, K. (2003) ''Lost solidarity' or 'changed solidarity': a comparative European view of family solidarity', Ageing \& Society, vol. 23, issue 5 pp. 537-560. $<$ http://journals.cambridge.org/download.php?file=\%2FASO\%2FASO23_05\%2FS0144686X030 01272a.pdf\&code $=59302852162 \mathrm{e} 0878 \mathrm{a} 467 \mathrm{~b} 20 \mathrm{ce} 538 \mathrm{f} 628>$

DYKSTRA, P. A. and FOKKEMA, T. (2010) 'Relationships between parents and their adult children: a West European typology of late-life families', Ageing \& Society, vol. 31, issue 4 pp. 545-569. <http://repub.eur.nl/res/pub/22441/typology\%20PD\%20TF\%20A_S11.pdf> 
ELDER, Glen H., Jr. (1985) 'Perspectives on the Life Course», In Elder G Jr Life Course Dynamics. Trajectories and Transitions, 1968-1980', Ithaca and London: Cornell University Press.

EUROBAROMETER (2007) Health and long-term care in the European Union, Special Eurobarometer, 283/Wave

67.3.<http://ec.europa.eu/public_opinion/archives/ebs/ebs_283_en.pdf>

EUROPEAN FOUNDATION FOR THE IMPROVEMENT OF LIVING AND WORKING CONDITIONS (2004) Health and Care in an enlarged Europe, Luxembourg: Office for Official Publications of the European

Communities.〈http://www.eurofound.europa.eu/pubdocs/2003/107/en/1/ef03107en.pdf>

FINCH, J. and MASON, J. (1993) Negotiating Family Responsibilities, London: Routledge.

FISHER, L. R. and EUSTIS, N. N. (1994) 'Care at home: family caregivers and home care workers'. In Kahana E, Biegel D E and Wykle M L (Eds.) Family caregiving across the lifespan, Thousand Oaks: Sage.

FORBAT, L (2005) Talking about Care. Two Sides of the Story, Bristol: Policy Press.

FRIEDMAN, L. S., Avila, S., Tanouye, K. and Joseph, K. (2011) 'A Case-Control Study of Severe Physical Abuse of Older Adults', Journal of the American Geriatrics Society, vol. 59, issue 3 pp.417-422. 
GLASER, K., TOMASSINI, C. and GRUNDY, E. (2004) 'Revisiting convergence and divergence: support for older people in Europe', European Journal of Ageing, vol. 1, no. 1 pp. 64-72.

GLUCKSMANN, M. and LYON, D. (2006) 'Confugurations of Care Work: Paid and Unpaid Elder Care in Italy and the Netherlands', Sociological Research Online, Vol.11, Issue 2.<http://www.socresonline.org.uk/11/2/glucksmann.html>

HABERKERN, K. and SZYDLIK, M. (2010) 'State care provision, societal opinion and children's care of older parents in 11 European countries', Ageing \& Society, vol. 30, issue 2 pp. 299-323. <http://www.suz.uzh.ch/ages/pages/PAGES-16.pdf>

HANK, K. (2007) 'Proximity and Contacts Between Older Parents and Their Children: A European Comparison', Journal of Marriage and Family, vol. 69, issue 1 pp. 157-173.

IGEL, C., BRANDT, M., HABERKERN, K. and SZYDLIK, M. (2009) 'Specialization between Family and State.Intergenerational Time Tranfers in Western Europe', Journal of Comparative Family Studies, vol. 40, issue 2 pp. 203-226.

KING, D. (2007) 'Rethinking The Care-Market Relationship In Care Provider Organisations', Australian Journal of Social Issues, vol. 42, no. 2 pp.199-212. 
LITWAK, E. (1985) Helping the Elderly: Complementary roles of informal networks and formal systems, New York: Guilford.

LITWAK, E., JESSOP, D. and MOULTON, H. (1994) 'Optimal Use of Formal and Informal Systems Over the Life Course'. In Kahana E, Biegel D E and Wykle M L (Eds.) Family Caregiving Across the Lifespan, Thousand Oaks: Sage.

LITWIN, H. and ATTIAS-DONFUT, C. (2009) 'The inter-relationship between formal and informal care: a study in France and Israel', Ageing \& Society, vol.29, issue 1 pp. 71-91.

LLOYD, L. (2003) 'Caring Relationships. Looking Beyond Welfare Categories of "Carers" and "Service Users". In Stalker, K. (Ed.) Reconceptualising Work with "Carers". New Directions for Policy and Practice, London: Jessica Kingsley Publishers, Ltd, pp.37-55.

LYON, D. and GLUCKSMANN, M. (2008) 'Comparative Configurations of Care Work across Europe', Sociology, vol. 42, issue 1 pp 101-118.

MOTEL-KLINGEBIEL, A., TESCH-ROEMER, C. and VON KONDRATOWITZ, H.-J. (2005) 'Welfare states do not crowd out the family: evidence for mixed responsibility from comparative analyses', Ageing \& Society, vol. 25, issue 6 pp. 863-882. <http://www.uv.es/=atortosa/statefamily.pdf>

MURACO, A. and FREDRIKSEN-GOLDSEN, K. (2011) '"That's what friends do": informal caregiving for chronically ill midlife and older lesbian, gay, and bisexual adults', Journal of Social and Personal Relationships, vol. 28, issue 8 pp.1073-1092. 
PENNING, M. J. (1990) 'Receipt of assistance by the elderly: hierarchical selection and task specificity', The Gerontologist, vol. 30, issue 2 pp. 220-227.

PENNING, M. J. and CHAPPELL, N. L. (1990) 'Self-care in relation to informal and formal care', Ageing \& Society, vol. 10, issue 1 pp. 41-59.

PIERCY, K.T. (2001) '"We couldn't do without them": The value of close relationships between older adults and their nonfamily caregivers', Generations, vol. 25, issue 2 pp. 41-47.

POPENOE, D. (1993) 'American family decline, 1960-1990: a review and appraisal', Journal of Marriage and the Family, vol. 55, no. 3 pp. 527-555.

QURESHI, H. and WALKER, A. (1989) The Caring Relationship. Elderly People and their Families, Basingstoke: Macmillan Education LTD.

REHER, D S. (1998) 'Family ties in Western Europe: persistent contrasts', Population and Development Review, vol. 24, no. 2 pp. 203-234.

RITCHIE, J. and LEWIS, J. (2003) Qualitative Research Practice - A Guide for Social Science Students and Researchers, Thousand Oaks: Sage.

SÃO JOSÉ, J. and WALL, K. (2006) 'Trabalhar e Cuidar de um Idoso Dependente: problemas e soluções', Cadernos Sociedade e Trabalho, VII: 119-154. 
SETTERSTEN, R. Jr. (2003) 'Propositions and Controversies in Life-Course Scholarship'.In Settersten R A Jr. Invitation to the Life Course. Toward new understandings of later life, New York: Baywood Publishing Company.

SILVERSTEIN, M. and BENGTSON V. L. (1997) 'Intergenerational solidarity and the structure of adult child-parent relationships in American families', American Journal of Sociology, vol. 103, no. 2 pp. 429-460.<http://www.techsociety.com/articles/AJSv103p429.pdf>

SIPILLÄ, J. and KRÖGER, T. (2005) 'Editorial Introduction: European Families Stretched between the Demands of Work and Care'. In Kröger T and Sipilä J (Eds.) Overstretched European Families Up Against the Demands of Work and Care, Malden, MA: Blackwell Publishing.

SOUSA, L. (2004) 'O recurso aos apoios formais: a família, o idoso e os cuidado(re)s formais'. In Sousa L, Figueiredo D and Cerqueira M, Envelhecer em Família. Os cuidados familiars na velhice, Porto: Âmbar.

TWIGG, J. and ATKIN, K. (2002) Carers Perceived. Policy and practice in informal care, London: Open University Press.

UNGERSON, C. (1990) 'The Language of Care Crossing the Boundaries'. In Ungerson, C. (Ed.) Gender and Caring. Work and Welfare in Britain and Scandinavia, Hertfordshire: Harvester Wheatsheaf. 
VASCONCELOS, P. (1998) 'Vida Familiar', in José M. Pais (coord.), Gerações e Valores na Sociedade Portuguesa Contemporânea, Lisboa: Instituto de Ciências Sociais.

WALL, K., ABOIM, S., CUNHA, V and VASCONCELOS, P. (2001) 'Families and support networks in Portugal: the reproduction of inequality', Journal of European Social Policy, vol. 11, no. 3 pp. $213-249$.

WARD-GRIFFIN, C. an d MARSHALL, V. W. (2003) 'Reconceptualizing the relationship between "public" and "private“ eldercare', Journal of Aging Studies, vol. 17, issue 2 pp. 189-208. 
Table 1 - Brief characterisation of the sample (these characteristics existed at the time of the interviews; in the cases where the carers were no longer providing care when they were interviewed, the information refers to the last caring experience).

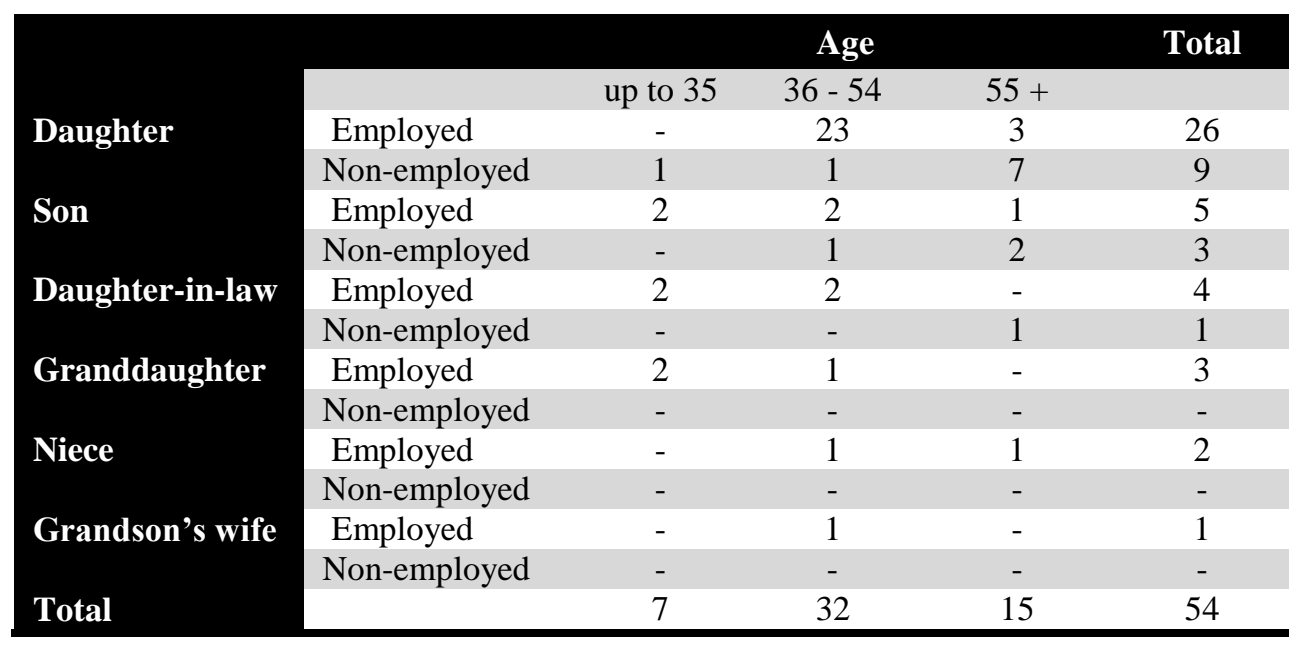

